\title{
Correction to: The Vector Electric Field Investigation (VEFI) on the C/NOFS
}

\author{
R. Pfaff ${ }^{1}$ (D) P. Uribe ${ }^{1} \cdot$ R. Fourre ${ }^{1} \cdot$ J. Kujawski ${ }^{1} \cdot$ N. Maynard ${ }^{2} \cdot$ M. Acuña ${ }^{1}$. D. Rowland ${ }^{1}$. \\ H. Freudenreich ${ }^{1}$ - K. Bromund ${ }^{1}$. S. Martin ${ }^{1}$. C. Liebrecht ${ }^{1}$ - R. Kramer ${ }^{3}$. F. Hunsaker ${ }^{1}$. \\ R. Holzworth ${ }^{4}$ - M. McCarthy ${ }^{4}$ - W. Farrell ${ }^{1}$ - J. Klenzing ${ }^{1} \cdot$ G. Le ${ }^{1} \cdot$ A. Jacobson ${ }^{4}$. \\ J. Houser ${ }^{1} \cdot$ C. Steigies ${ }^{1}$. J.-J. Berthelier ${ }^{5}$
}

Published online: 8 December 2021

(c) Springer Nature B.V. 2021

\section{Correction to: Space Sci. Rev. https://doi.org/10.1007/s11214-021-00859-y}

The original article was published with a reference error. The correct reference information should be noted as described below.

Where the incorrect reference appears:

J. Klenzing, F. Simões, S. Ivanov, R.A. Heelis, D. Bilitza, R. Pfaff, D. Rowland, Topside equatorial ionospheric density and composition during and after extreme solar minimum. J. Geophys. Res. Space Phys. 116(12), 1-10 (2011). https://doi.org/10. 1029/2011JA017213

The correct reference should be noted and replace with:

J.H. Klenzing, D.E. Rowland, R.F. Pfaff, G. Le, H. Freudenreich, R.A. Haaser, A.G. Burrell, R.A. Stoneback, W.R. Coley, R.A. Heelis, Observations of low-latitude plasma density enhancements and their associated plasma drifts. J. Geophys. Res. Space Phys., 116 (2011). https://doi.org/10.1029/2011JA016711

Noting this, this correction stands to correct the original article.

Publisher's Note Springer Nature remains neutral with regard to jurisdictional claims in published maps and institutional affiliations.

The original article can be found online at https://doi.org/10.1007/s11214-021-00859-y

\footnotetext{
R. Pfaff

Robert.F.Pfaff@nasa.gov

1 NASA Goddard Space Flight Center, Greenbelt, MD, USA

2 Mission Research Corporation, Nashua, NH, USA

3 Orbital Sciences Corporation, Beltsville, MD, USA

4 University of Washington, Seattle, WA, USA

5 CETP/IPSL, Saint-Maur, France
} 